\title{
A Geographic Theorization of Zongos in Urban Ghana: A
}

\section{Complex Systems Approach}

\author{
Joseph Mensah ${ }^{1}$ \\ Joseph Kofi Teye ${ }^{2 *}$
}

\begin{abstract}
While Zongos have become a permanent abode for many people, especially migrants in urban Ghana, the dynamics of these communities are quite poorly understood. This paper provides a geographic analysis of the formation of Zongos, drawing heavily on a complex systems approach to explore how various variables, including space, ethnicity, class, citizenship, migration and environmental processes intersect to form and sustain Zongos in Ghana. Essentially, the paper throws more light on the key factors that contribute to the spatial concentration of the urban poor in Zongos and concludes with the consequences of having the urban poor living in highly segregated and economically depressed neighbourhoods in Ghanaian cities. The paper argues that the formation of Zongos is not solely attributable to the fondness of migrants from northern Ghana to live among people of like background while in southern cities, but also because of the exclusionary machinations of the majority and their housing gatekeepers.
\end{abstract}

Keywords: Zongo, Migration, Urban Segregation, Complexity Theory, Ghana

\footnotetext{
${ }^{1}$ Faculty of Environmental and Urban Change, York University, Toronto. Canada

${ }^{2}$ Department of Geography and Resource Development, University of Ghana, Legon, Accra *Corresponding author email: jteye@ug.edu.gh
}

Ghana Journal of Geography Vol. 13 (2), 2021 pages 66- 95

https://dx.doi.org/10.4314/gig.v13i2.3 


\section{Introduction}

Critical theorizations of Zongos, which generally refer to temporary or informal settlements where migrants from northern Ghana live (Sarfoh, 1986), have become increasingly relevant to our understanding of life in cities across Ghana (and, indeed, across Africa). This is irrespective of whether we are exploring options to reduce environmental degradation, and the attendant health problems; seeking ways to alleviate poverty and homelessness; pondering over the proliferation of internet fraud; or examining the survival skills of the urban poor (Casentini 2018). While the etymology of the Zongo points to a transient space, it has become a permanent abode for many people in urban Ghana (Sarfoh, 1986). With the ongoing spatial turn and the growing popularity of geographic concepts and metaphors, such as spatial concentration, spatial marginalization, spatial justice, and the geographies of this, and the cartographies of that, the relevance of geographic theorizations in our understanding of the dynamics of the Zongo cannot be gainsaid. This paper offers some geographic insight into the formation of Zongos, drawing on the incipient science of complexity to explore how variables, including space, ethnicity, class, citizenship, migration and other socioeconomic and environmental processes intersect to form and sustain Zongos in Ghana. Essentially, the paper seeks to shed light on the key factors that feed into the dynamics and spatial concentration of the urban poor in the Zongos, and concludes with some insights into the consequences of the urban poor living in highly segregated and economically depressed neighbourhoods in cities.

As a field of study, Geography elicits different definitions with varying emphasis depending on context. Nonetheless, there is little doubt that much of what comes under the umbrella of the discipline deal with the study of the earth surface as a space within which the human population lives. Thus, with Geography, we do not study the earth surface, or any segment of it, in isolation 
of how humans use that space. Another common definition of Geography sees it as the study of the spatial variations and relationships of phenomena. Accordingly, Geography — at least, in partexamines spatial relationships, linkages, differentiations, and similarities between various phenomena. To the extent that the understanding of interrelationships constitutes one of the cruces of Geography, and the fact that the Zongo operates as an intricately interwoven entity, it is not hard to visualize the applicability of the incipient complexity theory in a geographic theorization of Zongos. "Complex systems," writes, "consist of diverse entities that interact both in space and in time" (Page 2009: 3); entities are considered complex as long as their components are diverse, inter-connected, interdependent and adaptable (P. 4). As we shall soon see, the Zongo exhibits most of the characteristics of a complex system.

Populated mainly by the urban poor, ethnic minorities, immigrants, transient workers, and itinerant traders, the Zongo is actually not that different from low-income enclaves in most Western cities today. Yet, while there are countless studies on such poor, segregated, ethno-racial neighbourhoods in the West (e.g., Massey and Denton, 1993; Peach, 1996; Kazemipur and Hall 1997 and 2000; Walks and Bourne, 2006; Phillips 2006 and 2007; Murdie and Skop, 2012), only a handful of research has been done on Zongos and other such segregated urban spaces in Africa. Notable exceptions here include the works of Tominson et al. (2003) and Lemanski (2006) in South Africa, K'Akumu and Olima (2007) in Kenya, and Agyei-Mensah and Owusu (2010) in Ghana. This is how Agyei-Mensah and Owusu cast the situation: "thus the debate has not engaged Africa as it does countries of Europe and America. In other words, very little work has been done on ethnic/racial urbanism in the developing world, particularly in sub-Saharan Africa" (p. 500).

The crucial question is why African geographers, sociologists and other social scientists have overlooked the spatial dimensions of poverty, social exclusion, and ethnic enclave formation in 
African cities for so long? To borrow the words of John Berger (1974: 40) Why have we allowed space to hide the consequences of these social phenomena from us for that long? The reason for this research gap is hard to pin down, given the many different and often contradictory scenarios that come to mind. First, the fact that ethnicity has assumed negative connotations in African postcolonial politics and regionalization has been cited as a reason for this gap. For instance, AgyeiMensah and Owusu (2010) contend that because many scholars see ethnicity as a source of tension in African politics - traceable to the legacy of colonialism, by which Africans were oppressed through various ethnic-laced divide-and rule tactics - they have steered clear of the topic altogether. Secondly, there are indications that "many national censuses do not even collect data on the ethnic make-up of the population, thus hindering any effective analysis of the subject matter" (Agyei-Mensah and Owusu 2010: 500). Arguably, the curricula of many African Geography departments, in particular, are partly to be blamed for this gap. For the most part, the thematic focuses of these Geography programs seem to be mainly on issues of the physical environment, such as climate change, environmental sustainability, land use, and resource development, than on matters of social and cultural geographies, including those of race, ethnicity, migration, sexuality, feminism, and queer theory. Additionally, one can argue that because postcolonial sub-Saharan Africa and its cities are predominantly populated by Blacks-with the notable exceptions of some major cities in the Republic of South Africa- the racial (and to some extent, ethnic) consciousness of post-colonial Africans is somewhat attenuated. It is along a homologous line of thinking that Mensah (2014) notes in his work on African-Canadians that: "it is upon reaching their destinations in Canada that many Black continental African immigrants usually become sensitized to matters of race. It is here that their Black African identity is subjected to forms of contestation, improvisation, hybridizations, metamorphosis, and sometimes 
denigration, depending on the context and the particular identity attribute(s) involved" (p. 23). In this context, it is unsurprising that research of ethnic segregation in African cities is slipping through the proverbial crack. Invariably, then, we have no choice but to draw heavily on the extant theories, most of which are based on Western cities, to help us understand how Zongos and other segregated spaces in African cities come about.

The paper is organized in four sections. Following this introduction, the next section provides some basic insight into what Zongos are-at least, in the context of Ghana and West Africa. Following this, we examine how the formation of immigrant residential patterns and ethnic enclaves have been theorized in the Western literature and identify some lessons to inform our understating of Zongos in Ghana. The third section, which forms the crux of the paper, is where we highlight the tenets of complexity theory and show the extent to which the dynamics of Zongos in Ghana are not that different from those of any complex system. The study concludes with some remarks on the merits and demerits of having poorly educated, low-income, ethnic minorities live in highly segregated communities, like the Zongos in Ghana.

\section{Understanding the 'Zongo'}

The term "Zongo" emanates from the Hausa word zango, which means "a temporary settlement," a "temporary sojourn, or "traveller's stop-over" (Casentini 2018: 452). The word was initially used to describe the outskirts of towns in southern Ghana and other parts of West Africa, where northern traders, most of whom were Hausa-speaking people from present-day Northern Nigeria, would stopover and trade with locals and other itinerant and seasonal traders from elsewhere in Ghana and beyond. Today, Zongos are common in both northern and southern Ghana. Some of the wellknown and sizeable Zongos in Ghana now are in cities such as Kumasi (e.g., Mossi Zongo) and Accra (e.g. Sabon Zongo) in the South. Nonetheless, regardless of where one finds the Zongo, its 
roots are tied to migration, commerce, transient life, cultural hybridity, and liminality. No wonder life in the Zongo continues to be dominated by traders, strangers, migrants, interpreters, and other transient workers. There are people whose genealogies are rooted in the Zongo for generations, and, thus, best described as permanent residents. The late Ghanaian historian, Kwame Arhin, was quite right in noting some decades ago, in his account of the role of the Zongo in the social and political life of Atebubu, that "a Zongo was not only a residential quarter, but more significantly a commercial institution [..a place where] residents acted as agents for traders....as hosts for incoming seasonal traders, as interpreters and generally as links between the diverse multilingual traders" (1971:73).

Unsurprisingly, populated mainly by migrants, transients and strangers-or people who are generally outside the mainstream of society based on their class, ethnicity, citizenship, and sometimes religion, the Zongo has often been stereotyped as an abode of criminals, fraudsters, and other social deviants, not to mention its common association with dirt, filth, overcrowding, and other forms of urban social and environmental degradation. Of course, as with most stereotypes, there are some truth to these attributions although, most of these negativities are overblown, as part of efforts by members of the majority to cast minorities as their dialectical polar opposite. As Mensah (2015) shrewdly notes, minorities are often used as a reference point for the identity formation of members of the majority by way of Hegelian negation-i.e., a dialectical principle by which we grasp the meaning of a concept by understanding what it is not. Thus, the presence of the migrant or the putative stranger in the Zongo is invariably drawn into the identity formation of mainstream Ghanaians (however defined) to paint the latter in a positive light, just as the former is cast in unflattering terms. In this context, the identity formation of members of the mainstream requires the presence of the stranger, without which the mainstreams identity formation is found 
wanting at a level akin to the famous master-slave dialectic: who can comprehend the concept of a master in the absence of the notion of a slave? We know from Foucault (1980 and 1982) that power is exercised not only by force, but also by discursive practices, one of which is the denigration of the minority population by the majority through negation. By stereotyping the Zongo and its residents as crime-prone, strangers, lazy and somehow inferior, the mainstream Ghanaian's identity implicitly becomes one of a host, law-abiding, hard-working, and superior. No wonder in Ghana the prevailing narrative is that most of the criminals are from Nigeria; just as in Nigeria, the prevailing mindset is that most of the criminals in their midst are Ghanaians.

\section{Theorizing Urban Segregation: Insights from the Global North}

"The spatial segregation and concentration of population groups," write Van Kempen and Özüekren (1998: 1631), "are as old as the hills." The earliest known major cities, including Babylon in ancient Mesopotamia and Aswan and Thebes in the Nile Valley were all segregated. So were the classical City States of the Greeks and the medieval, merchant, and the later industrial cities of Europe, as well as the pre-colonial and colonial cities of Asia, Africa, and the Americas (Van Kempen and Özüekren 1998; Moss 2011; Vance 1990). For the most part, the rich and powerful lived in distinct quarters, mostly located at the core of the city with the poor relegated to the fringes. Residential segregation then was institutionalized and enforced to remove the poor from the sight of the powerful (Engels, 1993; Van Kempen and Özüekren, 1998; Vance, 1990). Over the years, however, with the growth of egalitarianism and liberal democracy, especially in the West, strict de jure residential split between the powerful and the powerless began to wane. At the same time, it is common to find de facto residential segregation along the lines of class, race, ethnicity, and religion in most contemporary cities across the globe. In fact, de facto class-based 
residential segregation is gaining momentum in such cities as Lagos, Abuja, Accra, and Abidjan, with the proliferation of Western-style gated communities in the West Africa urban landscape.

Since the pioneering work of Robert Park and his colleagues at the Chicago School of Urban Ecology in the 1920s, the dominant account of the formation of ethnic enslaves and the residential patterns of immigrants has centered on the Spatial Assimilation Model (Park et al., 1925; Burgess et al., 1925). This model posits that new immigrants and ethnic minorities generally lack socioeconomic resources and often begin their lives in the city in poor neighbourhoods where they usually cluster in low-income housing among people of their own ethnic background. As they attain social and economic mobility over time, they move into higher quality housing in better neighbourhoods to live among members of the majority or mainstream society. With this model, over time, the spatial assimilation of immigrants and minorities mimics their socioeconomic and cultural assimilation. According to this theory, if a particular ethnic group continues to be spatially concentrated in a place, without the expected spatial assimilation over time, then something is amiss; perhaps, there is an acute socio-spatial exclusion of members of this group, pointing to a breakdown of the normal assimilation process.

The Spatial Assimilation Model has attracted criticisms over the years. In particular, critics are of the view that despite its usefulness for our understanding of the residential pattern of White, European immigrants in North American and Europeans cities, it is woefully inadequate in explaining the settlement patterns of visible minorities in general, and Blacks, in particular, in Western cities. For one thing, the presumption that the main, if not the only, barrier facing immigrants when it comes to where they live within the city concerns their socioeconomic status, or class, is hard to sustain in the case of Blacks in Western cities, given the extent of skin-colour 
racism in the housing markets. In the specific context of African cities, one has to contend with the prevalence of inter-ethnic conflicts and discrimination in housing.

Convinced that not all immigrant groups follow the spatial assimilation model, per the Chicago School, Johnston et al., (2006 and 2004) and Murdie and Skop (2010) have developed comprehensive tripartite typologies of immigrant residential pattern. The three components of the Johnston, Poulson and Forrest's version include the following: a plateau effect (Type 1 in Figure 1); an assimilation effect (Type 2 in Figure 1); and a continuing segregation effect (Type 3 in Figure 1). In this typology, the assimilation effect (Type 2) reflects the norm in the spatial assimilation model. Here, the immigrant group experiences some segregation at first, but the level of segregation decreases over time as its members attain residential propinquity with members of the host society. According to Johnston et al. (2006), this category is epitomised by the residential pattern of most of the southern European immigrant groups that settled in American cities in the late nineteenth and early twentieth centuries. With the plateau effect (Type 1), the level of segregation remains virtually the same (or plateaus out) for several decades, following an initial increase. The continuing segregation effect (Type 3) is where the level of segregation for the immigrant group continues to increase for several decades, as in the case of Blacks in America, for whom life in an increasingly segregated neighbourhood remains the norm. Scholars such as Massey and Denton refer to this pattern as "hyper-segregation" in their provocation book American Apartheid (1993). 


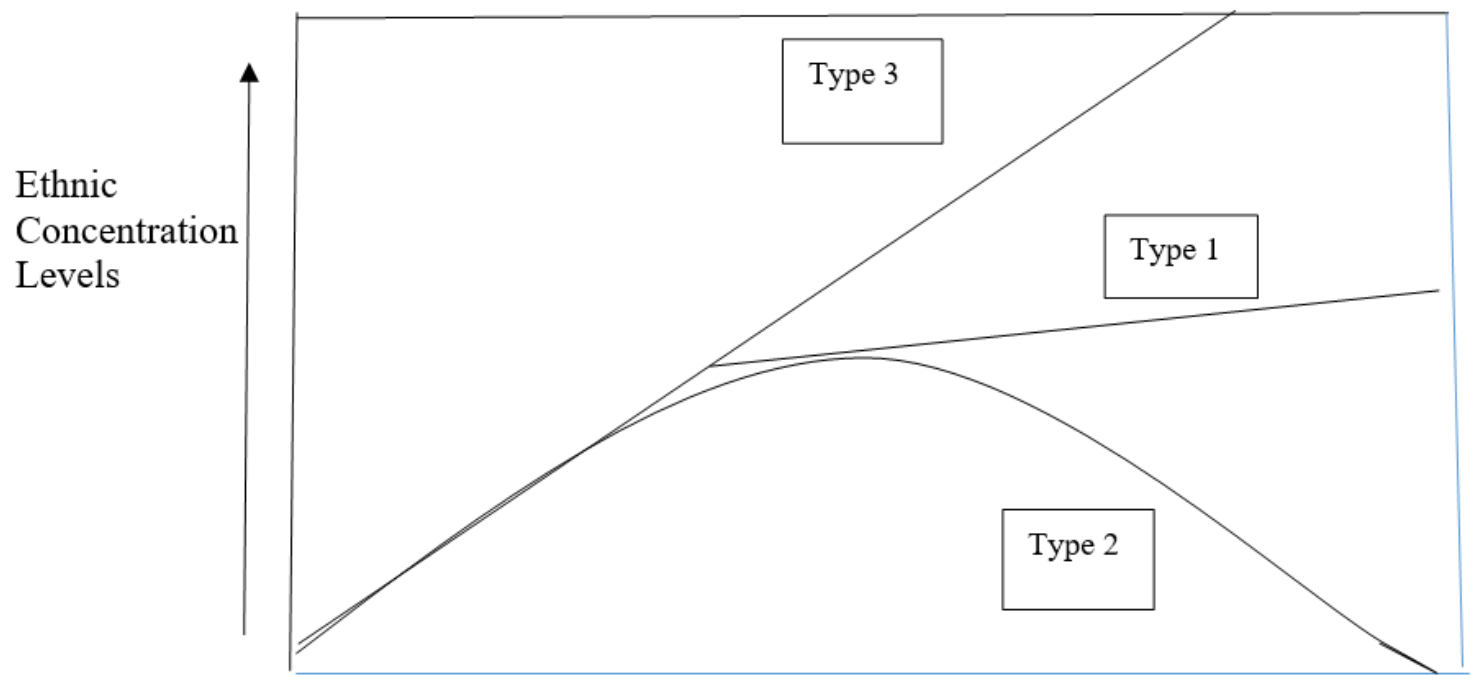

Figure 1: A Model of Changing Levels of Ethnic Residential Segregation over Time Years after establishment Source: Johnston, Poulsen and Forrest (2006: 391)

In a closely related tripartite typology, developed primarily in the context of urban Canada, Murdie and Skop (2012) categorize immigrant settlement patterns into: (i) those with no spatial concentration; (ii) those with spatial concentration for a limited time; and (iii) those with longterm or permanent spatial concentration . According to Murdie and Skop (2012), if the immigrant group shares many similarities in culture and socioeconomic background with the host society and, consequently, experiences no discrimination, it is likely to belong to the first category, and, thus, exhibit little or no spatial concentration. In the Canadian context, immigrants from Western European countries that have long been among the preferred group (e.g., immigrants of Dutch and German origins) belong to this category. However, if the immigrant group comes from Europe, but does not come from one of the "originally" preferred Western European source countries, it is likely to experience some level of discrimination and, consequently, to exhibit spatial concentration for a limited time (i.e., category ii). Notable examples in this second group include 
immigrants from Southern and Eastern European countries such as Spain, Italy, Portugal, and Poland. This second category of immigrants tends to follow the classic spatial assimilation model. The third category in the Murdie and Skop typology, which entails immigrant settlements of longterm or permanent spatial concentration, is epitomized by the settlement pattern of visible minority groups, with the case of Blacks in the United States and Canada serving as a classic example. For the most part, this third category comes about when the immigrant group has "a considerable degree of distinctiveness from the receiving society." Members of this group tend to differ substantially from the host society in terms of their racial, ethno-cultural, and socio-economic profiles, as well as in the initial resource they bring to the country. Unsurprisingly, members of this category experience high level of prejudice, stereotypes, and discrimination, especially in housing-hence, their long-term or permanent spatial concentration. Other noteworthy urban spaces exhibiting the characteristics of the third category are the Jewish enclaves and Chinatowns across United States and Canada.

From the preceding, it is quite clear that the formation of immigrant residential patterns and ethnic enclaves is hardly straightforward, and much of the extant theorizations have been about the situation in Western countries, with many analysts detailing cases of United States, Canada, and countries of Western Europe. To what extent do the existing theories and typologies apply to African cities? Are the tripartite typologies of Johnston et al. (2006) and Murdie and Skop (2012) useful for our understating of how Zongos are formed in Ghana? What lessons, deductions, caveats, and conclusion could be drawn from the theories and terminologies used to account for the formation of ethnic enclaves and the residential patterns of immigrants in Western cities to help us understand the dynamics of Zongo formation in Ghana? 
Undoubtedly, the preceding discussion has some utility for our understanding of how Zongos are formed in Ghana. For instance, as it is with immigrant enclaves in Western countries, notably in the United States, most of the immigrants, and even long-term residents, of Ghanaian Zongos are among the urban poor. However, people in Ghanaian Zongos are arguably better off than their counterparts in the bona fide slums, such as Ashiaman, Fadama, Aboabo, even though the two spatial entities (i.e., slums and Zongos) are often conflated in the literature as well as in the minds of the public. At the same time, even though both ethnicity and race are crucial factors in the formation of immigrant enclaves in Western countries, the latter is not much implicated in the formation of Zongos in Ghana. This is hardly surprising, as nearly all the Zongos are populated overwhelmingly, if not exclusively, by Black African immigrants from within and outside Ghana, just as the overwhelming majority of native Ghanaians are obviously Black Africans . Given these complications and caveats, it is unrealistic to expect a single model to capture all the nuances of how Zongos are formed in Ghana. In fact, the same can be said of any attempt to account for the formation of immigrant and ethnic enclaves in Western cities. That both Johnston et al.'s. (2006) and Murdie and Skop's (2012) theorizations on immigrant enclaves in Western cities are typologies, attest to the multifaceted nature of the factors underpinning immigrant residential patterns and enclave formations.

\section{Geographies of Zongo Formation in Ghana: A Complex Systems Approach}

In this section, we develop a novel approach to understanding the formation of Zongos, in particular, and the dynamics of Zongo life, in general. This is based on insights from the nascent theory of complex systems, or what has been called the "Complexity Theory", spearheaded by the likes of Mitchell Waldrop (1993), Mitchel Resnick (1997), John Holland (1999), Malcolm Gladwell (2000), Scott Page (2006; 2007) and Melanie Mitchell (2009). To make the discussion 
more focused, we zero in on the case of Ghana, with the knowledge that much of our theorization may apply to cities in other African countries with minor contextual tweaks.

With inspiration from complexity theory, we are able to capture the inherently diverse variables, phenomena, and entities that interact to form and sustain life in the Ghanaian Zongo. Among the key factors behind the formation of Zongos in Ghana are those concerning migration, citizenship and politics, culture and ethnicity, economic environment, social problems, and environmental problems. Clearly, these factors or components are not only diverse, and interdependent, but also capable of adapting to new stimuli and changes (Miller and Page, 2007; Page, 2009). As with any complex system, the Zongo operates like a network, with a collection of nodes and connections or edges to these nodes to form its ecosystem. Accordingly, in Figure 2 we have, for instance, the node of "culture and ethnicity" directly connected to those of "the economic environment" and "migration" on either side, and indirectly connected to the other three nodes, including "the citizenship and politics," "environmental problems," and "social problems."

The mechanisms by which these components and nodes operate together to constitute the Zongo is not that easy to discern. As in any complex system, these operations come about by way of what complexity scientists call emergence-i.e., "the spontaneous creation of order and functionality from the bottom up (Page 2009: 90)." Thus, to the complexity scientist, emergence is a process by which spatial patterns or structures are formed spontaneously from the bottom-up, often through self-organization without any overarching central control or superimposed outside force (Page 2009). This is how Scott Page analogises the process of emergence:

If you see a marching band in formation, that is top down organization; they're all getting marching orders, and they go exactly where they were told to go. If you see geese flying in a 'V,' you're seeing a structure that emerged without any sort of top down organization. You can spend all day in the park and you're never going to see the geese sitting in a little huddle where one person [or goose] is telling the other geese where to go (Page 2009:15). 


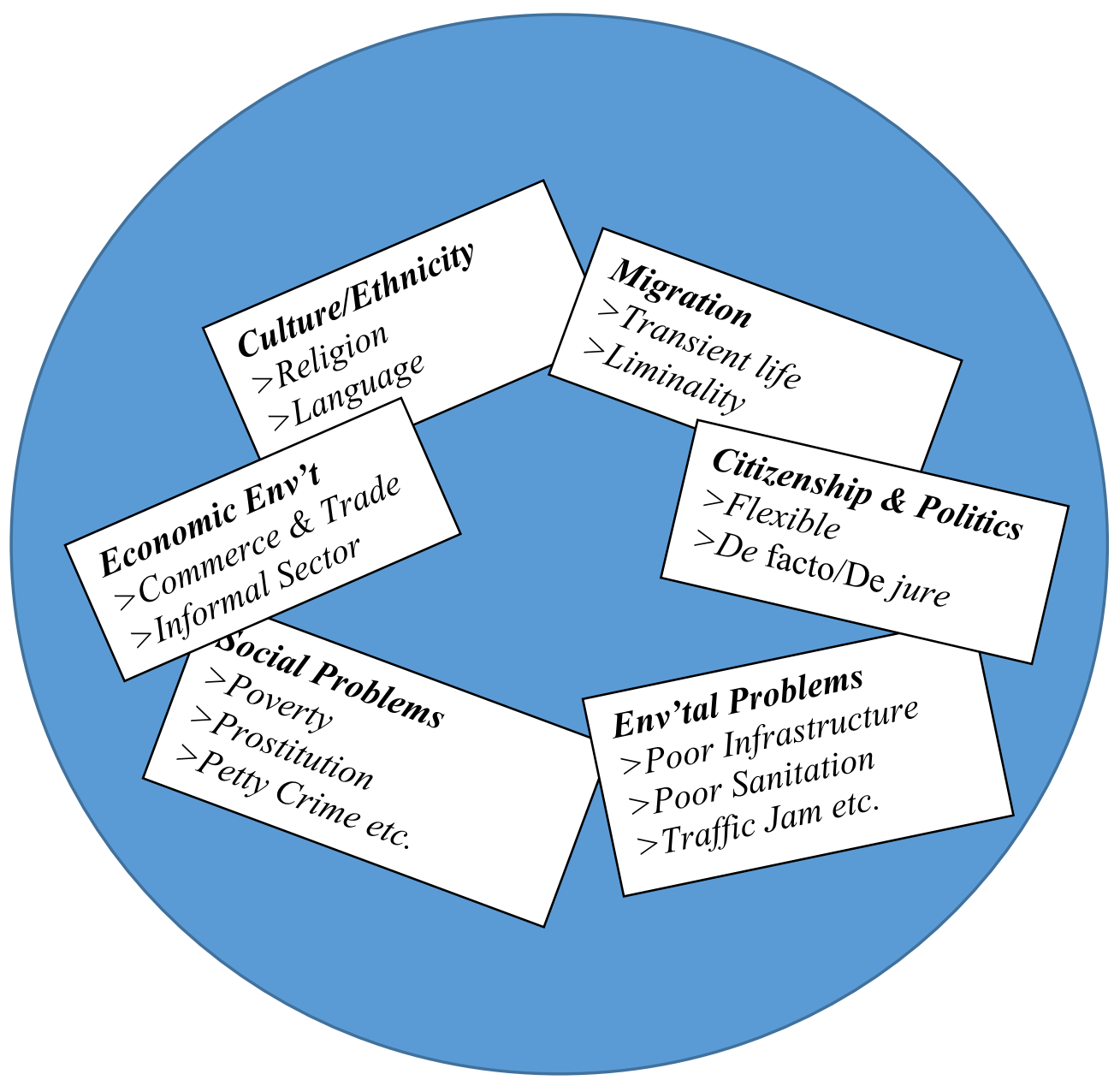

Figure 2: The Zongo in a Complex Theoretical Framework

Another intriguing feature of emergence is the fact that it often entails a situation where the macro differs from the micro, not only in scale but also in kind. Thus, in a complex system such as the Zongo, it is not always that whatever occurs at the macro-level is deducible from what occurs at the micro-level. As Thomas Schelling (2006), who won the Nobel Prize in economics, wrote in his famous book, Micromotives and Macrobehaviour, a bunch of people who are racially and ethnically tolerant could end up being segregated at the macro-level even though at the individual 
Ghana Journal of Geography Vol. 13 (2), 2021 pages 66- 95

or micro-level they have a high degree of racial or ethnic tolerance. Thus, the fact that one lives in an ethnic enclave, for instance, does not imply that one despises people of other ethnic background, who are living in other areas of a city. Similarly, many of the identified nodes and connections that constitute the Zongo come about by way of "self-organized criticality" (Page 2009: 209), which connotes a situation where "interacting agents self-organize into states that can produce large event." Put differently, "self-organized criticality" as used by the complexity theorist, points to how small events, such as a child crossing a road, can produce large disruptions, such as massive traffic jam. As theorized so far, the Zongo is a complex, but not a chaotic, system that is capable of producing various social, economic, cultural, and spatial patterns from the bottom up. Moreover, as a complex system, the Zongo is not a place in equilibrium; rather it a place of continuous change and novelty.

\section{The Dynamics of the Zongo as a Complex System}

In this section, we examine how the Zongo exhibits the dynamics of a complex system with some specificities from what occurs in Ghana. In particular, we profile the key components of the Zongo, as presented in Figure 2-including migration, culture and ethnicity, citizenship and politics, economic environment, environmental problems, and social problems - and shed light on how these components interact with each other to help account for the formation and sustenance of Zongos in Ghana. Anybody with some minimal familiarity with complexity theory would know that the six themes offered here are neither cast in stone nor exhaustive; rather they are malleable and best seen as heuristics. Thus, different analysts may not only deploy different themes, but may also use different terminologies, change the architectural arrangement of the themes in the system, or shift their emphasis from one theme to another, depending on context. 


\section{Migration}

With its etymology and genesis as "temporary settlements," the Zongo is invariably tied to migration. Indeed, Zongos are spaces within which migrants negotiate their socioeconomic and political positons in the context of their (im)migrant status, and its attendant rights, responsibilities, and challenges. While Ghanaian Zongos of yore were overwhelmingly populated by migrants from northern Ghana, in particular, and the Sahel region of West Africa, in general, today's Zongos include people of a far diverse mix of ethnicity. Still, the Zongo continues to serve as a hub of Islamic religion in many Ghanaian cities, attracting more Ghanaian and non-Ghanaian migrants of Islamic faith into its orbit in a self-reinforcing dynamic. With the Islamic religious ethos that every Muslim is a brother, it is not hard to see how established and long-time residents of Zongos would be eager, even if not obliged, to help new (im)migrants of the Islamic faith.

Zongos in Ghana have long been seen, or stereotyped, as spaces of critical environmental degradation, infrastructural deprivation, crime, and other social malaises, such as drug trafficking and prostitution (Casentini, 2018). While some of these attributions are overblown, like most stereotypes, there are some truth in them, as we shall soon see. Given their "transmigrant" base (Glick Schiller et al. 1995 and 1992), Zongos are a fecund source of cultural hybridity, often serving as a space in which people learn to live in settings that connect them to different countries, regions, cultures, and urban contexts. With this liminality, Zongo residents often try to meet their needs by bypassing the formal institutions of their host city, if not the host country. As a transitional space, the Zongo often attracts rural-urban migrants, who are seeking to have a foothold in big cities, such as Accra and Kumasi, since it offers far cheaper accommodation. Moreover, as the works of Owusu, Agyei-Mensah, and Lund (2008) show, Zongos and other lowincome communities in Accra (e.g., Nima, Sabon Zongo, La, and Accra New Town) tend to attract young people who are trying to embark on international migration. In addition to having cheap 
Ghana Journal of Geography Vol. 13 (2), 2021 pages 66- 95

accommodation and social support, Zongos often have more than their fair share of networks of people and civil society organizations that are tied to the migration industry and, thus, able to facilitate the procurement of visa and other travel documents - be them fake or real. At the same time, while Zongos are full of strangers, transients, and new immigrants, they still have long-term or permanent residents who are not migrants per se.

\section{Culture and Ethnicity}

As with nearly all African countries, Ghana is made up of many different ethnic groups, the leading among which are the Akan (47.5), Mole-Dagbon (16.6\%), Ewe (13.9\%), and Ga-Dangme (7.4\%); others (14.7\%) include the Guan, Gurma, Grusi, and Mande-Busanga (Ghana Statistical Services 2012). Each of the major ethnic groups in turn, is made up of many smaller or micro ethnicities. For instance, the Akan group includes the Ashanti, Bono, Akuapim, and Fanti, just as the MoleDagbon group is made up of the Mossi, Mamprusi, and Dagomba. Moreover, the spatial extent of many of these (micro)-ethnicities cuts across a number of neighbouring West African countries, including Togo, Cote D’Ivoire, Burkina Faso, Mali etc.

Estimates by Agyei-Mensah and Owusu (2010) show that while there were sizeable proportions of migrant populations in nearly all the 10 Administration Regions ${ }^{\mathrm{i}}$ of Ghana at the time of their research, each region was (and, indeed, continues to be) populated mainly by people of its indigenous ethnicity. We thus find the Akan, for instance, being the majority in Western, Central, Eastern, Ashanti, and Brong Ahafo regions of Ghana then (and indeed now), while the MoleDagomba were the predominant group in the Northern, Upper East, and Upper West regions. Perhaps the only notable, yet understandable, exception was the case of the Greater Accra Region, where Akans superseded the Ga-Dangme who are the indigenous people. This is understandable, 
since Greater Accra is home to Accra, the national capital, with an ethnic composition, which roughly reflects the proportionate share of the various ethnic groups in the country.

At the general level, what we have in Ghanaian Zongos is a situation where migrants from the northern regions of the country—notably, Upper East, Upper West, North East, Savannah, and Northern Regions (and even beyond) — settle in Zongos and other low-income communities in cities in the southern half of the country, including Techiman, Suyani, Kumasi, Accra, SokondinTakoradi, Cape Coast etc. At the same time, the major northern cities, such as Tamale and Bolegatanga, also have their own Zongos, most of which are populated by migrants from different parts of northern Ghana as well as the neighbouring Sahel regions of West Africa, including Burkina Faso, Mali, and Niger. The case of the Accra Metropolitan Area (AMA) is emblematic here (Table 1). Using data from Ghana’s 2000 Population and Housing Census, Agyei-Mensah and Owusu (2010) estimated the percentage share of the various ethnic groups in selected neighbourhoods in Accra, together with their respective Location Quotientsii. According to their estimates, whereas northern (im)migrants, mostly of the Mole-Dagbon ethnicity, constitute only a meager 5.6 percent of the total population of the Accra Metropolitan Area, the corresponding shares of this same group in the selected Zongos and low-class migrant communities, including Nima, Sabon Zongo, and Accra New Town, are 16.1\%, 13.8\%, and 8.9\%, respectively. Evidently, these Zongos and low-income communities in Accra have more than their expected share of northern migrants. The location quotients for Mole-Dagomba in these three low-income communities are 2.8, 2.5, and 1.6, respectively (Table 1), thus pointing to the clear overrepresentation of northern migrants in these low-income and Zongo communities. Zongos in other cities in mid- and southern Ghana, including those in Kumasi, Sekondi-Takoradi, Cape Coast have 
Ghana Journal of Geography Vol. 13 (2), 2021 pages 66- 95

fairly similar ethnic compositions, with a highly conspicuous presence of northerners - and, by extension, of Muslims.

Table 1: Percentage Ethnic Compositions and Location Quotients (LQ) of Selected Low-Income Migrant Communities (or Zongos) in the Accra Metropolitan Area, 2000

\begin{tabular}{|c|c|c|c|c|c|c|}
\hline Place & $\begin{array}{l}\text { Akan } \\
(\%)\end{array}$ & $\begin{array}{l}\text { Mole- } \\
\text { Dagbon } \\
(\%)\end{array}$ & $\begin{array}{l}\text { Ewe } \\
(\%)\end{array}$ & $\begin{array}{l}\text { Ga-Dangme } \\
(\%)\end{array}$ & $\begin{array}{l}\text { Others }{ }^{1} \\
(\%)\end{array}$ & Total \\
\hline Nima & 24.6 & 16.1 & 16.3 & 11.8 & 31.2 & \multirow{2}{*}{100} \\
\hline$L Q$ & 0.62 & 2.8 & 1.1 & 0.4 & 3.7 & \\
\hline Sabon Zongo & 36.7 & 13.8 & 11.7 & 11.3 & 26.4 & \multirow{2}{*}{100} \\
\hline$L Q$ & 0.9 & 2.5 & 0.8 & 0.4 & 3.1 & \\
\hline Accra New Town & 41.8 & 8.9 & 21.9 & 11.4 & 16.1 & \multirow{2}{*}{100} \\
\hline$L Q$ & 1 & 1.6 & 1.5 & 0.4 & 0.5 & \\
\hline Accra Metropolitan Area & 42 & 5.6 & 14 & 29 & 8.6 & 100 \\
\hline
\end{tabular}

${ }^{1}$ Other ethnicities include smaller groups such as Guan, Gurma, Grusi, and Mande-Busanga.

${ }^{2}$ Italiciced figures are the Location Quotients (LQ)

Source: Agyei-Mensah and Owusu (2010, p. 507 and 508).

\section{Citizenship and Politics}

Closely related to the (im)migrant and ethnic minority statuses of most Zongo residents, especially in the cities of southern Ghana, are palpable tensions surrounding their citizenship. Of course, those coming from northern Ghana are still Ghanaians, regardless of where they choose to settle within the country. At the same time, even though most of those who settle in the southern Zongos from northern Ghana have de jure citizenship, they struggle with their de facto citizenship due to ethno-linguistic and religious discrimination, as well as other forms of socioeconomic marginalization they face in the hands of many southerners. A good example here is the maltreatment meted out to girls and women from northern Ghana who work as head porters, or Kayayies, in southern cities such as Accra. Additionally, as (im)migrants, be them from northern Ghana or the neighbouring countries, they invariably lack the land base as well as the traditional chieftaincy system by which most Ghanaian society are governed, traditionally. Perhaps the worse 
of these citizenship-related challenges are faced by the (im)migrants from such neighbouring countries as Burkina Faso, Mali, Togo, Niger, Nigeria, and Cote D'Ivore, who lack both de jury and de facto citizenships by virtue of their non-Ghanaian nationality.

Notwithstanding these difficulties, many Zongo residents are able to use their trans-migrant or flexible citizenship-a-ala-Aihwa Ong (1999) to live in the world of liminality, moving in and out of Ghana, depending on how they see their socioeconomic circumstances at a particular time. Despite the fluidity of their identity and the fragility of their citizenship, and "despite this claimed attitude of non-involvement with local politics, Zongos are in fact an integral part of the contemporary Ghanaian political landscape, and have been since independence," writes Casentini (2018, p.460). With their abstruse position as "mediators" and "interpreters," (Casentini 2018, 460), or as people who are straddled between different cultures, simultaneously, Zongo residents' lives alternate between a desire to be fully integrated into Ghanaian politics, on the one hand, and the need to maintain their migration-rooted identity, on the other. Indeed, some Zongo residents are tactical in the way they deal with politics at both the local and national levels. There are instances where some would strategically downplay, if not deny outright, the authority of the municipal government or the local chieftaincy system, which is usually based on the indigenous ethnicity, in favour of some form of self-government. This way, they are able to avoid the common rules, regulations, and constrictions of the local government. There are also instances where some Zongo residents would intentionally gravitate more towards the national government, as against the local or municipal government, in a bid to enhance their chances for legitimacy and inclusion into the national polity and citizenship. Relatedly, over the years, some Ghanain politicians have tried, by way of various underhanded machinations, to win the political allegiance of Zongo residents during national elections. The worrisome situation involving the so-called Zongo boys in 
Ghana Journal of Geography Vol. 13 (2), 2021 pages 66- 95

Ghanaian politics, by which leading politicians use money and small gifts to co-opt young men for political violence and forced recruitment, is now well documented in the available literature (Amankwaah 2013; Casentini, 2018; Kobo, 2010).

\section{Economic Environment}

With their diverse backgrounds as permanent settlers, (im)migrants, and transients with varying degrees of citizenship, it is unsurprising that many of the people in Zongos, relative to their counterparts in other parts of the city, are among the urban poor (Casentini 2018; Agyei-Mensah and Owusu, 2010). As Amoako and Cobbinah (2011) and Owusu (2010) indicate, most Zongo residents make their living in the informal sector of the economy, with jobs such as woodworking, hairdressing, dressmaking, petty trading, and street vending of food and other items serving as their main sources of employment. While these Zongo residents try to eke out a living by any means possible, many are those who endure protracted spells of unemployment. Indeed, for a country like Ghana, high unemployment is nothing new, nationwide; at the same time, the attractiveness of big cities, such Accra and Kumasi, to rural folks continues unabated. Still, while in the city, many rural (im)migrants often end up in Zongos and kindred spaces, where they usually find some cheap accommodation and social support to survive.

The interrelationships between Zongo residents' economic situation, culture and ethnicity, migration status, and their spatial segregation, among other variables, are so dialectical that it is virtually impossible to clearly identify which of these factors are the causes and which ones are the effects of their straightened life circumstances. For instance, are most of these Zongo residents poor because they have little or no formal education or they are poor that is why they have little or no formal education? Are they poor because they are spatially segregated or they are poor that is 
why they are spatially concentrated? Is the residential segregation of Zongo residents mainly due to their economic class, with their ethnicity playing only a minor role in this spatial pattern or not?

After a careful empirical analysis of ethnic diversity in Accra, Agyei-Mensah and Owusu (2010) noted that, as in cities such as Tunis and Rabat, where "political tensions have not resulted in social fragmentation along ethnic lines," the residential segregation in Accra is mainly due to economic factors, and not ethnicity. This is how they put their argument at one point: "It is evident from the analysis that economic segregation is the organizing force underlying residential segregation in Accra, and that this operates through several social markers, one of which remains the ethnic history of migration to Accra" (Agyei-Mensah and Owusu, 2010: 513). Fair enough, but there is still no denying that the interplay between these variables - i.e., space, class, ethnicity, etc.—are far more complex and dialectical, with causes sometimes being interchangeable with the effects in any attempt to ascertain how Zongos, in particular, are formed and sustained over time. Clearly, then, the major components of the Zongo as a complex system (Figure 2), including culture of ethnicity, migration, economic environment, and citizenship and politics, etc., engender and feed into its social and environmental problems, as we shall soon see.

\section{Environmental Problems}

As in many African countries, cities in Ghana-notably, the big ones like Accra and Kumasicontinue to grow out of rural-urban migration. Meanwhile, the provision of basic infrastructure in major cities has remained woefully inadequate. This imbalance is even far worse in Zongos and other low-income neighbourhoods of the city, where overcrowding and poor educational, transportation, health, and sanitation facilities have become almost legendary (Songsore 2003; McGranahan et al. 1996). In fact, many Ghanaian Zongos are characterized by choked drains, inadequate and overflowing waste collection systems, and indiscriminate waste disposal practices 
Ghana Journal of Geography Vol. 13 (2), 2021 pages 66- 95

(AMA 2006; Ayee and Crook, 2003). This deplorable environmental situation is attributable to the biting poverty and the lack of hygiene and sanitation facilities, as well as the somewhat understandable dearth of incentives for households to engage in proper environmental practices. Other key factors include the lack of knowledge about environmental processes, and their associated health hazards, and the inadequate housing tenure among most Zongo residents (AMA 2006; Ayee and Crook 2003; and McGranahan and Songsore 1994).

From the standpoint of complexity science, these factors are so interrelated that it is virtually impossible to disentangle their individual impacts. Indeed, whether the main issues involved are even environmental, social, economic, or all of these factors is not easy to ascertain. Consider the relationships between poverty or socioeconomic class - broadly defined — and the lack of proper environmental management practices, for instance: Do poor household environmental practices and conditions arise because poor people cannot afford to live in acceptable environments? In addition, if that is the case, can we reasonably claim that the problem is even an environmental one (McGGranahan and Songsore 1995:5)? Moreover, as McGranahan and Songsore (1994: 5) further query: "Is it not patronizing to expect the unacceptably poor to live in acceptable home environment?" Indeed, can poor households afford to devote their scarce resources to improve the environment, even if they value the potential benefits of such improvement, especially given their constant struggles for the basic necessities of life, including food, shelter, and clothing? These are just a handful of the thorny questions we have to grapple with in our efforts to understand the urban environmental degradation underway in many Zongos of Ghana.

\section{Social Problems}

With their life in a class- and ethnic-laced segregated community, with minimal employment opportunities and maximal environmental degradation, it should not surprise us to know that 
Zongo residents face a number social problems and stereotypes. Casentini (2018: 456), for one, was quite right in asserting that "...the Zongo today remains an enduring stereotype in Ghanain society, where critical environmental and infrastructural conditions, and a high crime rate, are often linked to the presence of 'strangers' and the local discourse of migration." Arguably, the idea of the Zongo being a hub of criminality emanates from the majority's effort to denigrate the minority, as part of its attempt to see its own members in a positive light, relative to minorities, by way of dialectical negation. As Mensah (2015) points out, this is an old, tried and tested strategy, often deployed by majority populations against minorities in many societies. For instance, Ghanaians use it against the Nigerians in their midst; Nigerians use it against Ghanaians in Nigeria; Whites regularly use it against Blacks in U.S, Canada and elsewhere, just as the southerners in Ghana use it against northerners, especially in southern Ghana cities.

In any case, why would one be surprised to find high rates of crime in an environment of persistent un- and under-employment? Given the acute dearth of social amenities, good physical infrastructure, and economic opportunities in the Zongo, why would we be surprised to find chronic lawlessness, and all its attended social malaise, such as drug-pushing, hustling, petty thievery and even armed robbery, in the Zongo? Evidently, there is some truth to the negative stereotypes of the Zongo. At the same time, it will be patently erroneous to blame only the Zongo residents for these social and environmental problems, without paying any attention to the structural conditions they face in their daily lives in these enclaves. Any account of the problems of the Zongo that blames the resident per se, or exclusively, confuses the causes of the problems with the effects, by assuming that the problems are independent of the past and present material circumstances of the Zongo and its residents. 
Ghana Journal of Geography Vol. 13 (2), 2021 pages 66- 95

This is how William Ryan (1980), the American psychologist who coined the phrase "blaming the victim," puts this argument:

All this happens so smoothly that it seems downright rational. First, identify the social problem. Second, study those affected by the problem and discover in what ways they are different from the rest of us as a consequence of the deprivation and injustice. Third, define the differences as the cause of the social problem itself. Finally, of course, assign a government bureaucrat to invent a humanitarian action program to correct the difference (p. 476).

In a similar vein, Steinberg (1995) lamented in his analysis of the circumstance of Blacks in the US that: "Why social scientist think they have discovered something when they find that an indigent and marginalized population lives according to 'different rules' from the middle class is itself perplexing" (emphasis in original; p. 142).

The fact that crime and other social and environmental problems are far more prevalent in the Zongo also has something to do with the self-selection and cumulative causation dynamics of the Zongo formation, beyond what we can attribute to structural and individual factors. For one thing, with so many poorly education, low-income people density concentrated in an area-mostly through self-selection - it is only a matter of time that many of these social problems would feed into themselves, through cumulative causation, to form a vicious cycle of a sort. And who can deny the fact that ethnic discrimination and other social and spatial injustices perpetrated by the majority population against minorities in the Zongos, especially in the grand scheme of urban planning in major cities in southern Ghana, are also to be blamed here. 


\section{Conclusion: Consequence for Zongo and City Residents}

To have so many poorly educated, low-income people of ethnic minority background living in a segregated community clearly comes with some socioeconomic and political burdens. However, urban segregation is, indeed, nothing new; but the specific question here is: What are the consequences and burdens wrought upon the Zongo residents for living in such a place? Given the lack of local resources and employment opportunities in the Zongos, residents often endure long spells of un- and under-employment, as well as problems of crime and safety. Moreover, with residents of Zongos often socializing mainly with people in their neighbourhoods, mainly because of their spatial entrapment, many of them do not see the need to integrate into the host society much. Invariably, this undermines their civic participation in the broader society and truncate their social cohesion and solidarity with others beyond the confines of the Zongo. Notwithstanding such concerns, it bear noting that life in the Zongo is not all negative; it has its positive dimensions. For one thing, with their spatial concentration, Zongo residents are able to maintain their cultural values and practices, strengthen their social networks and, ultimately, enhance their intragroup social capital. Additionally, with their spatial concentration, these Zongo residents, most of whom are Northerners, are able to attain the requisite critical mass of population to support their ethnicbased economic enterprises and sociocultural and religious institutions. In addition, ethnic enclaves provide some level of defense or "cushion" against ethnic discrimination meted out to the Zongo residents by members of the mainstream society. What many Ghanaians would not admit openly is the prevalence of ethnic discrimination, especially by Southerners against Northerners, most of whom are of Islamic religion.

Clearly, then, the formation of Zongos is not solely attributable to the fondness of northerners to live among people of like background while in southern cities such as Accra, but also because of 
the exclusionary machinations of the majority and their housing gatekeepers, such as landlords, real estate agents, and community leaders. Thus, the ensuing socio-spatial exclusion is a two-agent process: on the one hand, is the majority, serving as the putative excluder and, on the other is the minority, who constitutes the excluded. At its core, socio-spatial exclusion of people in the Zongo brings the issue of fairness, social justice, human dignity and, indeed, Ghanaian citizenship, or the lack thereof, for many people of northern ethnicity who live in various southern cities into bold relief. The question here is: Can we candidly claim to be treating these Zongo residents as bona fide Ghanaian citizens, when most of them are compelled to live mainly among themselves in resource-strapped enclaves? Put differently, have we simply resigned ourselves to seeing and treating these Zongo residents as second-class citizens for all practical purposes? Against the backdrop of such questions, the much-touted Ghanaian liberal democracy is effectively given the proverbial black eye; and this black-eying process is not merely symbolic, but also material in its consequence, as it ends up weakening the life chances, loyalties, solidarity, and security of most Zongo residents.

\section{References}

Agyei-Mensah, S., \& Owusu, G. (2010). Segregated by neighbourhoods? A portrait of ethnic diversity in the neighbourhoods of the Accra Metropolitan Area, Ghana. Population, Space and Place, 16(6), 499-516.

AMA (Accra Metropolitan Assembly). (2006). Medium-term development plan 2006-2009. Accra: AMA.

Amankwaah, C. (2013). Election-related violence: The case of Ghana. Uppsala: Nordiska Afrikainstitutet.

Amoako, C., \& Cobbinah, P. (2011). Slum improvement in the Kumasi metropolis, Ghana: A review of approaches and results. Journal of Sustainable Development in Africa, 13(8), 150-170.

Arhin, K. (1971). Strangers and Hosts: A Study in the Political Organisation and History of Atebubu Town. Transactions of the Historical Society of Ghana, 12, 63-82. 
Ayee, J., \& Crook, R. (2003). " Toilet wars": urban sanitation services and the politics of publicprivate partnerships in Ghana" Institute of Development Studies (IDS), Working Paper Series \# 213. Brighton: IDS

Berger, J. (1974). The Look of Things. New York: Viking.

Burgess, E. W. (1925). The growth of the city in Park, RE, Burgess EW and McKenzie RD (eds), The city: Chicago: University of Chicago Press.

Casentini, G. (2018). Migration networks and narratives in Ghana: a case study from the Zongo. Africa, 88(3), 452-468.

Foucault, M. (1980). Power/knowledge: Selected interviews and other writings, 1972-1977. New York: Pantheon Books.

Foucault, M. (1982). Interview with Michel Foucault on space, knowledge and power. Skyline (March), 17-20.

Ghana Statistical Service (GSS) (2012). 2010 Population and Housing Census: Summary Report of Final Results .Accra: Ghana Statistical Service

Gladwell, Malcolm. (2000). The tipping point. How little things can make a big difference. New York: Brown and Company.

Graham, H. D. (1998). Stephen Steinberg. Turning Back: The Retreat from Racial Justice in American Thought and Policy. Boston, Mass.: Beacon. 1995. Pp. xi, 276. \$25.00. The American Historical Review, 103(3), 1002-1002.

Halli, S. S., Kazemipur, A., \& Douchant, C. (2000). The new poverty in Canada: Ethnic groups \& ghetto neighbourhoods. Canadian Journal of Urban Research, 9(2), 231.

Holland, J. H. (2000). Emergence: From chaos to order. New York: Oxford Universit Press.

Johnston, R., Poulsen, M., \& Forrest, J. (2004). The comparative study of ethnic residential segregation in the USA, 1980-2000. Tijdschrift voor economische en sociale geografie, 95(5), 550-569.

Johnston, R., Poulsen, M., \& Forrest, J. (2006). Blacks and Hispanics in urban America: Similar patterns of residential segregation? Population, Space and Place, 12(5), 389-406.

K'akumu, O. A., \& Olima, W. H. (2007). The dynamics and implications of residential segregation in Nairobi. Habitat International, 31(1), 87-99.

Kazemipur, A., \& Halli, S. S. (1997). Plight of immigrants: The spatial concentration of poverty in Canada. Canadian Journal of Regional Science, 20(1), 2.

Kazempur, A. (2000) The new poverty in Canada: ethnic groups and ghetto. Toronto: Thompson Educational Publishing.

Kobo, O. (2010). 'We are citizens too': the politics of citizenship in independent Ghana. The Journal of Modern African Studies, 67-94.

Lemanski, C. L. (2006). Desegregation and integration as linked or distinct? Evidence from a previously 'White'suburb in post-apartheid Cape Town. International Journal of Urban and Regional Research, 30(3), 564-586.

Massey, D. S. \& Denton, N. A (1993). American apartheid: Segregation and the making of the underclass. Cambridge, MA: Harvard University Press

Massey, D. S., \& Denton, N. A. (1989). Hypersegregation in US metropolitan areas: Black and Hispanic segregation along five dimensions. Demography, 26(3), 373-391.

McGranahan, G., \& Songsore, J. (1994). Wealth, health, and the urban household: weighing environmental burdens in Jakarta and Accra. Environment: Science and Policy for Sustainable Development, 36(6), 4-45.

Mensah, J. (2014). Black continental African identities in Canada: Exploring the intersections of 
Ghana Journal of Geography Vol. 13 (2), 2021 pages 66- 95

identity formation and immigrant transnationalism. Journal of Canadian Studies, 48(3), 529.

Mensah, J. (2014). The Black, continental African presence and the nation-immigration dialectic in Canada. Social Identities, 20(4-5), 279-298.

Miller, J. H., \& Page, S. E. (2007). Social Science in Between, from Complex Adaptive Systems: An Introduction to Computational Models of Social Life. Introductory Chapters.

Mitchell, M. (2009). Complexity: A guided tour. New York: Oxford University Press.

Moss, T.J (2011): African development: Making sense of the issues and actors. Boulder, CO: Lynne Rienner Publishers.

Murdie, R. A., \& Skop, E. (2012). Immigration and urban and suburban settlements. Immigrant geographies of North American cities, 48-68.

Ong, A. (1999). Flexible citizenship: The cultural logics of transnationality. Durham, NC: Duke University Press.

Ostrom, E. (2008). The Difference: How the Power of Diversity Creates Better Groups, Firms, Schools, and Societies. By Scott E. Page. Princeton: Princeton University Press, 2007. 448p. \$27.95 cloth, \$19.95 paper. Perspectives on Politics, 6(4), 828-829.

Owusu, G. (2010). Social effects of poor sanitation and waste management on poor urban communities: a neighborhood-specific study of Sabon Zongo, Accra. Journal of Urbanism, 3(2), 145-160.

Owusu, G., Agyei-Mensah, S., \& Lund, R. (2008). Slums of hope and slums of despair: Mobility and livelihoods in Nima, Accra. Norsk Geografisk Tidsskrift-Norwegian Journal of Geography, 62(3), 180-190.

Page, S. E. (2006). Path dependence. Quarterly Journal of Political Science, 1(1), 87-115.

Page, S. E. (2009). Understanding complexity. Chantilly, VA: Teaching Company.

Park, R. E., Burgess, E. W., \& McKenzie, R. D. (1925). 1925: The city. Chicago: University of Chicago Press.

Peach, C. (1996). Good segregation, bad segregation. Planning Perspectives, 11(4), 379-398.

Phillips, D. (2006). Parallel lives? Challenging discourses of British Muslim selfsegregation. Environment and Planning D: Society and Space, 24(1), 25-40.

Phillips, D. (2007). Ethnic and racial segregation: a critical perspective. Geography Compass, 1(5), 1138-1159.

Poulsen, M., Johnston, R., \& Forrest, J. (2004). Is Sydney a divided city ethnically?. Australian geographical studies, 42(3), 356-377.

Resnick, M. (1997). Turtles, termites, and traffic jams: Explorations in massively parallel microworlds. Cambridge, MA: MIT Press.

Rothenberg, P. S., \& Struhl, K. J. (Eds.). (1975). Philosophy now: an introductory reader. New York: Random House.

Sarfoh, J. A. (1986). The West African zongo and the American ghetto: Some comparative aspects of the roles of religious institutions. Journal of Black Studies, 17(1), 71-84.

Schelling, T. C. (2006). Micromotives and macrobehavior. New York and London: W.W. Norton \& Company.

Schiller, N. G., Basch, L., \& Blanc, C. S. (1995). From immigrant to transmigrant: Theorizing transnational migration. Anthropological Quarterly, 48-63.

Schiller, N. G., Basch, L., \& Blanc-Szanton, C. (1992). Transnationalism: A new analytic framework for understanding migration. Annals of the New York Academy of Sciences, 645(1), 1-24. 
Songsore, J. (2003). The urban housing crisis in Ghana capital: The state versus the people. Ghana Social Science Journal, 2(1), 1-31.

Steinberg, Stephen (1995): Turning back: the retreat from racial justice in American though and policy. Boston: Beacon.

Tomlinson, R., Beauregard, R., Bremmer, L., \& Mangcu, X. (Eds.). (2003). Emerging Johannesburg: perspectives on the postapartheid city. New York: Routledge.

Van Kempen, R., \& Şule Özüekren, A. (1998). Ethnic segregation in cities: new forms and explanations in a dynamic world. Urban Studies, 35(10), 1631-1656.

Waldrop, M. M. (1993). Complexity: The emerging science at the edge of order and chaos. New York: Simon and Schuster.

Walks, R. A., \& Bourne, L. S. (2006). Ghettos in Canada's cities? Racial segregation, ethnic enclaves and poverty concentration in Canadian urban areas. The Canadian Geographer/Le Géographe Canadien, 50(3), 273-297.

\footnotetext{
${ }^{1}$ In early 2019, the number of Administrative Regions in Ghana was increased from 10 to 16, with the creation of the Ahafo, Bono East, Savannah; North East, Oti, and Western North Regions.

${ }^{1}$ Location Quotients $(\mathrm{LQ}=(e i / t i) /(E / T)$ : where $e i$ and $t i$ are the ethnic and total populations in a community or neighborhood unit $i ; E$ and $T$ are the ethnic and total population in Accra. If the percentage of an ethnic group in a community is similar to its corresponding percentage in Accra overall, the LQ will be 1; if the percentage share of a group in the neighborhood or community is greater than the corresponding percentage in Accra in general then LQ will be greater than 1; and, conversely, if it is less than that of Accra the LQ will be less than 1.
} 